\title{
Science education and computational thinking - adapting two projects from classroom learning to emergency distance learning
}

\author{
Ana Silva', João Silva1, Catarina Gouveia', Eduarda Silva', \\ Pedro Rodrigues ${ }^{1}$, António Barbot ${ }^{1}$, Ana Quintas ${ }^{2}$, Daniela Coelho ${ }^{3}$, \\ ${ }^{1}$ School of Education of the Polytechnic Institute of Porto, Portugal, ORCID ID: 0000-0003-4720-824X \\ ${ }^{1}$ School of Education of the Polytechnic Institute of Porto, Portugal, ORCID ID: 0000-0002-0220-116X \\ ${ }^{1}$ School of Education of the Polytechnic Institute of Porto, Portugal, ORCID ID: 0000-0003-0213-5809 \\ ${ }^{1}$ School of Education of the Polytechnic Institute of Porto, Portugal, ORCID ID: 0000-0002-4094-9101 \\ ${ }^{1}$ School of Education of the Polytechnic Institute of Porto, Portugal, ORCID ID: 0000-0001-8862-2805 \\ ${ }^{1}$ School of Education of the Polytechnic Institute of Porto, Portugal, ORCID ID: 0000-0001-9915-1519 \\ ${ }^{2}$ Paço Basic School, Portugal \\ ${ }_{3}^{3}$ Maria Manuela de Sá 2nd \& 3rd Cycles Basic School, Portugal, ORCID ID: 0000-0003-4273-4654 \\ Email: anacatcruzsilva@gmail.com,jvcrs92@gmail.com, catarinagouveia13@outlook.com, \\ duda_ruby@hotmail.com, pedrorodrigues@ese.ipp.pt, antoniobarbot@ese.ipp.pt, \\ anacquintas27@gmail.com,daniela.coelho@aesmi.pt
}

\begin{abstract}
The sudden need for an adaptation of two science projects based on the changes that the COVID-19 pandemic brought to the education system in Portugal, transitioning from classroom learning to distance learning, led to a reorganization within the structure of these projects in order to implement them, maintaining the same objectives.

Both projects have the main goal to develop computational thinking, with the first project having simultaneously the aim to also develop an environmental awareness through an initiation to programming by way of implementing challenges regarding the same topic, within 1st grade pupils, namely recycling and reducing single use waste, based on a mix method research. The second project, based on the quantitative method research, constitutes the assembly and implementation of a weather station, based on the microprocessor Micro:bit, at the service of the science curricula contents within 5th grade students, with regard to abiotic factors and its influence on animals and plants.
\end{abstract}

Key words: Computational thinking, Distance learning, Programming, Science education, Sensors

\section{Introduction}

Given the growth development of the School's capacity in terms of the ability to bring together in a classroom a variety of technological resources, as well as the children's familiarity with a whole range of tech gadgets, emerges the necessity of developing dynamic lessons using the technological means to avail the already existing student's skills within these resources and, simultaneously, to prepare them for the use of other resources and mechanisms applied to real world problems, expanding the range of options which students face at the end of the compulsory education. The need for computational thinking, described by Wing (2008) as "taking an approach to solving problems, designing systems and understanding human behavior", emerges through the necessity of taking advantage of the already existing technologies which use seeks to answer for common, every day, real problems. In the same article, Wing goes further and questions how and when should computational thinking be initialized within the educational system, stating that in order to ensure a "common and solid basis of understanding and applying computational thinking for all", then that should be done starting in early years of education (Wing, 2008). In fact, there are also reports of computational thinking and computer science that, introduced in elementary years, proved to be effective in the improvement of "cognitive ability, mathematics, reasoning, and problem solving" (Clements, Battista, \& Sarama, 2001; Liao \& Bright, 1991, in Tran 2019), while also augmenting, as long-term effects, sustained attention, self-direction, and increased enjoyment in inquiry-based activities (Clements, 1987, in Tran 2019).

According to Quadros Flores, Escola \& Peres (2009), prepared schools and teachers are needed to attend to the necessities of a "society of knowledge, a network society, where children of digital generation live". Such promotion and preparedness should happen under a set of strategies that aim as much for the student's curricula learning success as well as skills. This way, the teacher's performance in the 
construction of strategies around technological resources implies, according to Flores (2009), "well defined objectives, well outlined strategies, a participative approach, innovative actions associated to projects and developed under a network of partnerships". The same author also states that a teacher's careful performance in activity planning, contributes to "involved students, more responsible in their own knowledge building and more committed to the tasks in hand", leading to a "more personalized education, student centered".

The pooling of resources that serve the Natural Sciences curriculum, allows to develop skills related to scientific literacy, insofar as the construction of projects that answer real world problems, makes that the intervention in problem solving of local, regional, national and even global scope (Vieira, Tenreiro-Vieira, 2011) are important so that the same practices have meaning to the child. The divergence can be decreased based on the relation between the Science curriculum and its orientation according to "more humanistic (CTS focused perspectives) because of its connection to real contexts" (Martins, 2002).

Therewithal, according to Costa et al. (2012), recognizing the transformation potential of technologies to the process of learning and teaching is the first step for the curriculum and school programs start integrating this kind of cognitive abilities. Of all the abilities, logical thinking and problem solving are the most important ones for the several areas of knowledge and the ones which will be significant for personal and social development and even more so as our society develops around technology. Therefore, programming skills seem fundamental and that was the motivation behind the development of the projects to develop computational thinking.

Computational thinking is a process of logical reasoning that includes characteristics such as formulation of organization problems and logical analysis of data; automated solutions through algorithms; identification, analysis and implementation of solutions and generalization and transfer of the solution process found to solve other problems (Wing \& Lee, 2014).

Within the limitations of the emergence of the COVID-19 pandemic, the first project has been implemented on an extracurricular schedule, where the students had the first contact with programming through an online game with simple commands, by means of a smartphone application, progressing to a game designed by the teacher through the block-based visual programming Scratch platform. The students applied computational thinking and consolidated science concepts.

These games were wielded through synchronous online classes through the online platform adopted by the school, in which the students controlled a screen casted from the teachers' computer. This adaptation followed a change in the number of sessions projected originally, from seven to only four. The implementation had to be reduced, based on the limited time of contact with the students as well as the lack of resources and the restriction of the teacher's presence to guide and observe the students in its own discovery of the related educational tools.

The second project underwent modifications in its structure, having the exigency of adapting some project's stages to be able to implement it nonetheless without losing track of its main objective. The project's main stages consisted of the weather station assembly, code writing and results' analysis by the students. The adaptation resulted in only being able to implement the later stage of the project, with the first two phases having been delegated to the teacher. The methodology adopted consisted of video recording the weather station all set up and working, while also recording the data given by the Micro:bit. It was granted the possibility for the students to choose and vote in which abiotic factor to measure and the location in which they wanted for the weather station to be placed, through an online form, using Google Forms within the Google Classroom, the school's designated online platform.

This article aims to find the effectiveness of developing computational thinking using epistemological tools at the service of the science curricula contents. The study's main questions revolve around the referred article aim, which consists of the following: "Can environmental education be enhanced through the development of computational thinking?" and "In which way can the microprocessor and its sensors allow teaching Sciences curriculum contents and skills?". From these questions, the problems that surfaced starting the projects concerned with what tools could be used to implement the purposes that were cited before. Later, right before implementing both projects, the problems persisted, but in a different form, asking ourselves now how could both projects maintain the same objectives while changing the structure in which it would happen - from classroom based to distance learning projects.

\section{Method}

As stated by Barbot (2017), "a problem is a need that exists in some context and that does not allow for something to function as well as desired", our main problem constituted the need to implement ways of developing computational thinking, bringing new tools to the classroom and bind them with the current 
Sciences curriculum. That being so, it emerges the questions to each project, along with the objectives outlined. Therefore, the first investigation project was developed in a 1st grade class, having objectives inside of the obstacles that distance teaching brings, such as promoting logical thinking and problem solving while developing, at the same time, computer thinking and simultaneity sustainable conscience through challenges of initial programming, wanting to answer the question: "Can environmental education be enhanced through the development of computational thinking?". The second investigation project emerges as a means to a possible answer to the question: "In which way can the microprocessor and its sensors allow teaching Sciences curriculum contents and skills?", while, simultaneously, having the objective of promoting greater usage of technological resources while teaching curriculum contents and contributing to student involvement in the construction of an educational resource.

For both projects, the data collection consisted mainly through observation and analysis of the surveys implemented. The first project was based most on the qualitative method since it was focused on an understanding and reflection of the students' interactions and relationships (Meirinhos \& Osório, 2010). Also, the quantitative method was used once a questionnaire was applied as well. Whereas in the second project it was based more on the quantitative method since it analysed actual data mainly through the surveys implemented at the end of each activity that was possible to obtain the students' input regarding the satisfaction, their options and opinions concerning the next steps, the actions and the locations. The work done by the students in the first session could also be analysed upon the reception of their work through the Google Classrooms platform.

While both projects aim to develop computational thinking, the initial plans for the implementation had to be adapted due to the circumstances of the COVID-19 pandemic and, being carried out in different educational settings that also lead to different ways of execution.

Project 1 went through adaptations regarding the number of participants and the limitation to make use of some resources outlined initially, although it was possible to set up synchronous lessons through Microsoft Teams platform; while Project 2 was implemented in an asynchronous environment, through the Google Classrooms online platform, which faced problems regarding the communication channel with the pupils that generated a strain in the initial objectives: the project's focus shifted from assembling + coding + implementing to a lesson to just coding + implementing, having the teacher carrying out the first step of the project.

In the previous context, before the COVID-19 pandemic, the project was going to be developed in the normal schedule of the class including all members of the class. However, because of the new situation the project had to be done in extracurricular hours. In the new context, the students started to have synchronized classes every day from 10:30 am to 11:30 am. Also, they had to do one task every day after class and every Monday they had 1 hour from 2:30 pm to 3:30 pm class for another project.

Before the pandemic adaptation every student of the class was going to be part of this project, namely, 21 students but not wanting to overwhelm the pupils and to have a good and close accompaniment a small sample of four students of the class were selected randomly to participate in this project through a synchronized class every Thursday afternoon for 40 minutes from 2:30 to 3:10. This way they had some time to rest from the other project activity already mentioned.

Table 1. Comparison between the initial project and its adaptations for the Project 1

\begin{tabular}{|c|c|c|}
\hline Sessions & Old context & New context \\
\hline $1^{\text {st }}$ session & Program your friend & $\begin{array}{l}\text { Talk with the students } \\
\text { Program the Lightbot } \\
\text { 4th of June, } 2020 \\
2: 30 \text { pm to } 3: 10 \text { pm }\end{array}$ \\
\hline $2^{\text {nd }}$ session & Program the Bluebot & $\begin{array}{l}\text { Program the Lightbot } \\
23^{\text {rd }} \text { of June, } 2020 \\
2: 30 \text { pm to } 3: 10 \text { pm }\end{array}$ \\
\hline $3^{\text {rd }}$ session & Program the Bluebot & $\begin{array}{c}\text { Program the Lightbot on Scratch and talk with } \\
\text { the students } \\
25^{\text {th }} \text { of June, } 2020 \\
2: 30 \text { pm to } 3: 10 \text { pm }\end{array}$ \\
\hline $\begin{array}{l}4^{\text {th }} \text { session } \\
5^{\text {th }} \text { session }\end{array}$ & Program the Lightbot & --- \\
\hline $6^{\text {th }}$ session & Program the Lightbot & --- \\
\hline
\end{tabular}


As the projects changed, the method for the investigation also changed. As seen on the previous table (Table 1), initially, the project would have seven sessions where all of them were going to have direct participant observation and analysis from the teacher, furthermore it would be done a pre-test and a posttest for further compassion of results and, lastly, a brief questionnaire to all of the students (corresponding to 21 students) for them to evaluate their opinion and interests towards the sessions.

However, in the new context the sessions had to be reduced because the already mentioned limited time that the students had but also because of the impracticality of some resources such as the Bluebot and the Micro:bit, ending up with three sessions, the first one were the teacher applied a direct participant observation, guiding the students to better understand the game, the second with no intervention from the teacher, where the students' were observed and the third were the students played also with no intervention and applied their knowledge about recycling having the teacher only intervened to talk about the items available for recycling. Also, in every session a small interview was made to the students about their interest in the session and in the end for data tool collecting it was made a questionnaire for the guardians of the students about their thoughts about the developing of the skills we were working on.

According to Hill \& Hill (1998), the questions made in the questionnaire can have different goals. Therefore, in its construction it is possible to ask respondents for information about facts, opinions, attitudes, preferences, values, satisfactions and also reasons, motives, among others. Furthermore, it's important to reveal an adaptation made to suit the recycling content and at the same time keeping the character of the previous game the "Light Bot" and context. This was achieved using the platform "Scratch": [https://Scratch.mit.edu/projects/405064551]. So, the first project followed a qualitative method, because it focused on an ideology of understanding and reflection on interactions and relations, where the investigator invested in the observation and the analysis of the observed data (Meirinhos \& Osório, 2010).

For the 2nd project it was projected a number of 4 classroom learning sessions: the first three sessions through a science club like method, whose participants would be selected based on their own interest; and the last session, a classroom lesson focused on implementing the weather station fully assembled and programed at the service of the science curriculum through the study of the influence of abiotic factors on animals, their morphological and behavioral adaptations (see Table 2 below).

Table 2. Initial plan for the Project 2

\begin{tabular}{cc}
\hline Session & Contents \\
\hline $1^{\text {st }}$ session & Weather station assembly (science club) \\
$2^{\text {nd }}$ session & Coding and programming the Micro:bit + Weather:bit (science \\
club) & Manipulation and analysis of data retrieved by the Weather \\
& station \\
$3^{\text {rd }}$ session & Classroom learning lesson about abiotic factors \\
\hline
\end{tabular}

In the first session, the students would be able to assemble the weather station, learn about its mechanisms and sensors, the abiotic factors they monitor and how this monetization it's possible. This first session would focus only on the mechanical part of the project, which would be important to explain that without the electrical and electronic fraction its use is very limited, if not, completely unusable. The second session would focus on both the Micro:bit microprocessor board as well as the Weather:bit (weather shield extension), its programming through coding and how it can serve as a bridge between the abiotic factors that are to be measured, the sensors and us, the teacher and students, who are trying to make sense of the data, which would be retrieved and analyzed on the $3^{\text {rd }}$ session. The Micro:bit is, this way, the translator between every component.

With the surge of the COVID-19 pandemic, the initial plan had to be revised and adapted to the changes that the pandemic brought to the educational context in the Portuguese educational system, as well as the individual changes and responses in each setting. In the case of the educational setting in which this project was implemented, it did not support synchronous lessons, so the adaptations had to be made through an asynchronous context. This was seen possible throughout the creation of websites. These 
websites could host text information, images and video that allowed for two sessions, having the first been cancelled and carried out by the teacher. The two sessions consisted of an activity regarding the study of abiotic factors and its influence on animal morphological and behavioral adaptations and the Micro:bit coding and programming, although in a more undemanding way, and its results through pre-recorded video. This adaptation led to the inversion of the previously outlined plan (see Table 3 below).

Table 3. Adaptations regarding educational context post-pandemic changes for the Project 2 Session Contents

\begin{tabular}{c}
\hline Weather station assembly carried out by the teacher \\
$1^{\text {st }}$ session \\
$\begin{array}{c}\text { Asynchronous activity in a lesson regarding abiotic factors (its } \\
\text { effects on animals' morphological and behavioral adaptations) }\end{array}$ \\
Asynchronous coding and programming the Micro:bit + \\
Weather:bit
\end{tabular}

At the end of each session, the students were able to answer a questionnaire regarding their own learning through the weather station as well as give an input about what to do next with the whole resource: where to place and what to measure. Students' answers contributed to the planning of the second session, which influenced the videos shared on the website. At the end of the second session, they were again able to answer a questionnaire regarding the whole project.

This constituted a method based on an action-research plan, which was contemplated as the most feasible and logical to the main focus of the sessions involved, in the way that it "supports the praxeological development of the teachers/educators, as it accepts them as actors and authors (...) in the consequent theoretical production regarding their educational options and recognizing the value of their conceptual logic" (Mesquita-Pires, 2010).

\section{Findings}

Regarding the Project 1, analyzing the responses from the students' guardians, as observed in the Table 4 below, it was considered unanimously the importance that children should learn how to use electronic devices and browse the internet as well as developing skills as programing and computational thinking, considering that those skills are important for the future of the students, only disagreeing on which age it should start being applied.

Table 4. Project 1 questionnaire's responses.

\begin{tabular}{lc}
\hline \multicolumn{1}{c}{ Questions } & Responses \\
\hline $\begin{array}{l}\text { Do you consider that it is important for your student to } \\
\text { learn how to surf the internet as well as how to handle } \\
\text { electronic devices? }\end{array}$ & $100 \%$ answered yes \\
po you think it is important for your student to develop & $100 \%$ answered yes \\
programming skills? & \\
How impactful do you think these navigation, handling and & $100 \%$ answered "very important" \\
\hline
\end{tabular}

With the options being "1-2 years"; "3-4 years"; "5-7 years"; "8-10 years" and "10-14 years", regarding which age kids should learn how to use electronic devices and browse the internet, the guardian with secondary education answered "5-7 years", the one with a graduate degree answered "5-14 years" (choosing three of the options), and the guardian with the master's degree answered "8 - 10 years". When asked at which age children should start developing programming and computational thinking skills, the 
guardian with secondary education answered "5-7 years", the guardian with a graduation degree answered "5-14 years" (choosing three of the options) and the guardian with the master's degree answered "10 - 14 years". Moreover, all guardians revealed that all students were always very enthusiastic and happy after the sessions, showing that this kind of resources are motivating and could be included more frequently in ordinary classes.

Concerning the Project 2, and considering mainly the students' answers on the final questionnaire, as it can be observed in Table 5 below, it was unanimously stated that the children liked programming with the Micro:bit, answering "Really enjoyed it" (44,4\%) and "Enjoyed" (55.6\%), having also the option to answer "Enjoyed a little", with no answers whatsoever. When asked about the difficulty of coding the Micro:bit, the answers were divided between "Very easy" (44.4\%) and "Easy" (55.6\%), just like in the question before, with also having the option to answer "Hard" and "Very hard", although no one opt for those options. Finally, concerning the question if they would program and code again, 77.8\% answered "Yes" and 22,2\% chose the answer "Maybe", while also having the option to answer "No", but with no answers. Regarding the weather station itself, the children were more interested in one factor in favour of the rest: when asked about what abiotic factor they enjoyed the most exploring, the majority (58,3\%) answered "The wind", while 33,3\% opt for "The temperature" and only 8,3\% chose "The water". Finally, concerning the likeness within the students to use the Weather Station again, the vast majority chose the answer "Yes" (88,9\%), 11,1\% opt for "Maybe" and no student answered "No".

Table 4. Project 2 questionnaire's responses.

\begin{tabular}{|c|c|c|c|c|}
\hline \multirow{2}{*}{$\begin{array}{c}\text { Questions } \\
\text { Question }\end{array}$} & \multicolumn{4}{|c|}{ Answers } \\
\hline & $\begin{array}{l}\text { Really enjoyed } \\
\text { it }\end{array}$ & Enjoyed & $\begin{array}{l}\text { Enjoyed a } \\
\text { little }\end{array}$ & \\
\hline $\begin{array}{c}\text { Did you enjoy programming with the } \\
\text { Micro:bit? }\end{array}$ & $44,4 \%$ & $55,6 \%$ & $0 \%$ & \\
\hline Question & Very difficult & Difficult & Easy & Very easy \\
\hline $\begin{array}{l}\text { How difficult did you find } \\
\text { programming with the Micro:bit? }\end{array}$ & $0 \%$ & $0 \%$ & $55,6 \%$ & $44,4 \%$ \\
\hline Question & Yes & Maybe & No & \\
\hline Would you try programming again? & $77,8 \%$ & $22,2 \%$ & $0 \%$ & \\
\hline Question & $\begin{array}{l}\text { The } \\
\text { temperature }\end{array}$ & The wind & The water & \\
\hline $\begin{array}{l}\text { What abiotic factor did you enjoy } \\
\text { exploring the most? }\end{array}$ & $33,3 \%$ & $58,3 \%$ & $8,3 \%$ & \\
\hline Question & Yes & Maybe & No & \\
\hline $\begin{array}{c}\text { Would you utilize the Weather Station } \\
\text { again in the future? }\end{array}$ & $88,9 \%$ & $11,1 \%$ & $0 \%$ & \\
\hline
\end{tabular}

\section{Results, Conclusions and Recommendations}

Given what we aimed to find through the implementation of both projects as described in this essay, we are most pleased with what we could accomplish during these stressful times for the educational system. Both projects were outlined before the COVID-19 pandemic brought the constraints it did so for the last period of the educational year and the changes and adaptations constitute itself the most valuable experience and result that we can take from this whole project. As Barbot (2017) stated, "the main purpose of the research is more to understand and to improve than to test hypotheses".

On the Project 1's first session, children were given a small amount of guidance about the controls and they were also given time to explore the resources by themselves. Having given just the same tips as "thinking step by step" and to try to "imagine the position of the robot", so that in the second and third session they had all the tools to play with autonomously, having verified exactly that. It was observed that the students learned very fast and actually enjoyed learning by try and error and, in one instance, one of the students was always telling the others what to do and they showed that they didn't want the help. In 
general, they were very enthusiastic and excited to learn not only the subject in question but also in the context of distance education.

It was interesting that the guardian with the higher degree answered that children should start interacting and developing computational thinking later than the one with the lowest degree. However, this would be more reliable and interesting to analyze if the sample was broader to state if the same result would still maintain. In regard to the sample, it was adverse that it could not be larger, and it got even smaller as one of the four students, which initially had a computer, which was crucial to participating in the project, wasn't able to access the computer because one of the student's parents started needing it for work.

Concerning the second project, although less transparent, it was through the students' answers that the project was able to move forward and allowed for an initial and basic understanding of coding and programming a microprocessor, what is implied and what results from its tweaks. From the students' answers we were able to see from their perspective, how they were perceiving the tasks at hand and how they were overcoming their difficulties. It was complicated to get a real-time sense of how students were behaving during the tasks, yet it was easy to understand, through their answers if the tasks were being completed or not. On the first session, students were able to send their work through Google Classrooms, which made it easier for us, teachers, to understand how the students were able to relate the Weather Station's information with the science subjects.

Through the questionnaires, it was possible to gather that the majority of the students enjoyed exploring the wind the most. This can maybe be explained with the fact that the wind sensors are more appealing to the eyes, which gives the perception that it can be more ludic. "The temperature" option comes next, which was also presented in a digital form: the numbers would change in the Micro:bit's LED screen. Finally, "The water" was the abiotic factor that was chosen the least, maybe explained by the fact that it was less explored by the Weather Station, because this project was implemented in the transition of May and June in the northern region of Portugal, where, in this time of the year, the rainfall can be null.

Regarding this project in particular, we believe that the objectives were fulfilled, having the weather station merged seamlessly with the Sciences curriculum.

Overall, it was verified that it is possible to promote computational thinking, while simultaneously enhancing content learning in a distance learning model, even with all the limitations. Regarding the first project, it could be optimized if the initial plans could be implemented, as it could be applied from the concrete to the abstract as it was noticed a lot of difficulties from the students when they had to navigate in the game because they still don't have the spatial orientation developed. As for the second project, the assembly and the programming are some aspects that could be improved with more preparation from a student perspective, as it was applied with few tools that not much has done to shorten the distance that the context was forced upon. It was, without doubt, a challenging process of adaptation in both projects, with their own educational contexts and set of rules, but could not have happened without it, as is great the importance that experimental work plays as a 'stimulating element to awaken the students' interest not only to the discussions regarding the specific Sciences' subjects, as for being aware of the necessity of its continuous development" (Malheiro, 2016).

The changes in the educational paradigm, caused by the COVID-19 pandemic, proved the emergence of developing computational thinking, familiarizing children with technological and electronic tools, for an easier adaptation to possible future changes. It is also important to prepare students for the challenges of the job market of tomorrow, relating a set of skills that, interconnected, will develop an appropriate posture towards the problems that are yet to emerge. The education can also aim for a future proofing attitude, which constitutes a strategy of "ensuring that (students) acquire a wide range of tools or capabilities that will allow them to thrive in an increasingly complex global job market" (Milligan, Luo, Hassim \& Johnston, 2020).

\section{References}

Barbot, A. (2017). Problems and questions: elucidation and relevance for research and teaching (Chapter 18), from: Lopes, J. B; P., Cravino J; Cruz, E.; Barbot, A.. 2017. Teaching Science: Contributions of Research for Planning, Practice and Professional Development. ed. 1, ISBN: 978-1-53612-381-4. New York: Nova Science.

Costa, F. A., Rodriguez, C. L., Cruz, E. \& Fradão, S. (2012). "Repensar as TIC na educação: o professor como agente transformador. 1 ed. Lisboa: Santillana.

Hill, M. M. \& Hill, A. (1998). A Construção de um Questionário. Fundação para a Ciência e a Tecnologia.

Lee, I. (2014). “CSTA Computational Thinking Task Force”. 
Malheiro, J. (2016). Atividades experimentais no ensino de ciências: limites e possibilidades. ACTIO. 1 (1). 108-127. Curitiba, Brasil.

Martins, I. (2002). Problemas e perspectivas sobre a integração CTS no sistema educativo português. Revista Eletrónica de Enseñanza de las Ciencias, 28-39.

Meirinhos, M. \& Osório, A. (2010). O estudo de caso como estratégia de investigação em educação. EDUSER: 2. Instituto Politécnico de Bragança.

Mesquita-Pires, C. (2010). The action research to support the professional development of teachers. EDUSER: Vol. 2 (2). Instituto Politécnico de Bragança.

Milligan, S. K., Luo, R., Hassim, E., \& Johnston, J. (2020). Future-proofing students: What they need to know and how to assess and credential them. Melbourne, Australia: Melbourne Graduate School of Education, the University of Melbourne: Melbourne.

Quadros Flores, P., Escola, J., \& Peres, A. (2009). A tecnologia ao Serviço da Educação: práticas com TIC no $1^{\text {o }}$ Ciclo do ensino Básico. In VI Conferência Internacional de TIC na Educação - Challenges (pp. 715-726). Universidade do Minho, Braga.

Vieira, R. \& Tenreiro-Vieira, C. (2016). Educação em Ciências e Matemática com Orientação CTS Promotora do Pensamento Crítico.

Wing, J. (2006). “Computational Thinking”. Communications of the ACM, 49, (3), 33-35.

Wing, J. (2008). "Computational thinking and thinking about computing". Philosophical Transactions of The Royal Society A. 